\title{
Particle Sizes and Thermal Insulation Properties of Some Selected Wood Materials for Solar Device Applications
}

\author{
S. S. Oluyamo and * O. R. Bello \\ Department of Physics, Federal University of Technology, P. M. B. 704, Akure, NIGERIA
}

\begin{abstract}
This study investigates the thermal properties of some selected wood materials found in the rain forest of South Western Nigeria. These wood species are Alstonia boonei (Ahun), Pterygota macrocarpa (Oporoporo), Milicia excels (Iroko), Pterocarpus (Osun), Celtics zenkeri (Ita) and Pterocarpus mildraedii (Ure). Particle sizes of $300 \mu \mathrm{m}, 600 \mu \mathrm{m}$ and $850 \mu \mathrm{m}$ were sieved out from each of the different wood materials of the six varieties of wood species. The samples were machined to appropriate disc shape using fabricated hydraulic-press mould. The modified Lee's disc apparatus was used to determine the thermal conductivities of the samples. The result shows that thermal conductivity of the selected wood shavings change with particle sizes. Except for the Pterygota marcrocarpa, other samples had least thermal conductivity values at $600 \mu \mathrm{m}$ particle size ranging from 0.045-0.067 $\mathrm{Wm}^{-1} \mathrm{~K}^{1}$. This range fall within the thermal conductivity values of commonly used solar flat plate collectors. In addition, $600 \mu \mathrm{m}$ pose the best insulation among the particle sizes considered. Hence, the selected wood materials could be used as industrial insulators as their thermal conductivity values fall within the range of existing industrial thermal insulators. The materials could also serve as good potential devices as heat resistant.
\end{abstract}

Keyword: Thermal conductivity, Particle size, Lee's disc, Industrial insulator

\section{Introduction}

Industrial insulators are essential materials in engineering design, finishing of machine and other equipment. It is essential to use thermal insulator in the lagging of thermal energy storage systems to ensure maintenance of set temperature within the system such that heat losses to the surrounding can be minimized [1]. Thermal insulators find its application in devices like solar flat-plate collector, refrigerator, incubator, car upholstery, building artist and many more. Thermal insulation is specifically used in obstructing the flow of heat between an enclosure and its surroundings [2]. Materials used as thermal insulator largely depend on the thermal properties such as thermal conductivity, thermal resistivity, thermal absorptivity, thermal diffusivity as well as specific heat capacity.

Rock wool and fiber glass are commonly used as thermal energy storage systems due to their low thermal conductivity. However, increasing demand for the use of industrial thermal insulator coupled with inherent high cost and health implication of such materials calls for the search for alternative thermal insulating material [3, 4].

Over the years, different materials have been used as thermal insulators based on their thermal insulation properties, availability, cost, density and environmental friendliness. Hence, material with low value of thermal conductivity comparable with existing industrial insulator is of global interest. Commonly used materials as thermal insulator include calcium silicate, mineral fibre, fibre glass, Polyurethane, polystyrene, plastic foam e.t.c. Natural products and industrial waste such as cotton wool, clay, sawdust, rice husk among others found to exhibit low thermal conductivity values are also useful as solar device materials. Due to serious environmental degradation caused by industrial activities and the need to conserve energy and resources, various research efforts had been focused towards the utilization of industrial waste around the world [5]. Various attempts are on-going to develop locally available materials with suitable structural and energy conserving properties. [6] conducted a study on the thermal properties of Ceiba pentandra cotton and reported that the properties of the cotton are comparable with that of already established insulating materials for solar flat plate collector and refrigerator. Species of timber and timber products are being investigated in term of their thermal properties for suitability as energy conserving materials $[7,8]$.

Sawdust is a major bye product of sawmill industry. The major challenge of this product is the mode of disposal. Most often, burning is the method usually adopted by sawmillers for the disposal of this by product. Apart from causing serious pollution, it is not environmentally friendly. Sawdust from different wood species had been noted to exhibit varying interesting thermal conductivity values. An investigation on the thermal and physical properties of eight varieties of sawdust showed that the samples had different thermal conductivity values [9]. This further suggests that thermal conductivity of wood vary from species to species. Thermal conductivity is an essential attribute when offering energy conserving building products. Wood has excellent heat insulation properties and low thermal conductivity values which equates to greater heat insulating 
properties [10]. Thermal properties are strongly influenced by the physical structures of the deposits, particle size, porosity and sintered condition $[11,12]$.

This study focused on determining the insulation property of sawdust obtained from six wood species. Particle sizes of samples as they affect the thermal conductivity were also considered.

\section{Sample Preparation And Experimental Method}

The samples used for this study were obtained from Road-block sawmill industry in Akure South Local Government Area of Ondo State, South Western Nigeria. Sawdust from six (6) different wood species were collected from the sawmill. These include; Alstonia boonei (Ahun), Pterygota macrocarpa (Oporoporo), Milicia excels (Iroko), Pterocarpus (Osun), Celtics zenkeri (Ita) and Pterocarpus mildraedii (Ure). These materials are waste product from sawmill industry and it is in large quantity that disposing this waste has become a huge task for saw millers. Samples collected were sun-dried to reduce moisture contents. Each sample was separated through mechanical sieve-shaker into different particle sizes: $300 \mu \mathrm{m}, 600 \mu \mathrm{m}$ and $850 \mu \mathrm{m}$. To determine the thermal conductivity, modified Lee's disc technique was adopted because of its experimental simplicity and availability of the apparatus. After sieving each samples into three different particle sizes, a total of eighteen (18) samples were prepared for analysis. Hydraulic press mould was used to prepare the samples into appropriate disc shape. The resulting shape of the samples is shown in Figure 1. Each of the samples was mounted on the Lee's disc apparatus, powered through $6 \mathrm{~V}$ regulated dc supply. Both the Voltage $(\mathrm{V})$ and Current (I) flowing through the set-up were measured and recorded via digital multimeter at interval of 5 minutes until the temperature attained steady state.

As usual, the temperatures of the brass disc in the apparatus at steady state were fitted into equation 1 to obtain the thermal conductivity $(\mathrm{k})$ of the samples. Details of this method can be sourced from the liteatures [13, $14,15]$.

$$
k=\frac{e d}{2 \pi r^{2}\left(\theta_{B}-\theta_{A}\right)}\left[a_{S} \frac{\theta_{A}+\theta_{B}-2 \theta_{a m b}}{2}+2 a_{A}\left(\theta_{A}-\theta_{a m b}\right)\right]
$$

nd

$$
e=\frac{V I}{a_{A}\left(\theta_{A}-\theta_{a m b}\right)+a_{S} \frac{\left(\theta_{A}-\theta_{a m b}\right)+\left(\theta_{B}-\theta_{a m b}\right)}{2}+a_{B}\left(\theta_{B}-\theta_{a m b}\right)+a_{C}\left(\theta_{C}-\theta_{a m b}\right)}
$$

here $a_{A}, a_{B}, a_{C}$ and $a_{S}$ are the exposed surface area of disc $\mathrm{A}, \mathrm{B}, \mathrm{C}$ and the sample respectively when mounted on the apparatus. Also, $\theta_{A}, \theta_{B}, \theta_{C}$ and $\theta_{a m b}$ are the temperatures of the discs and the ambient at steady state. In equation (1); $d$ and $r$ represent the thickness and radius of the samples.

\section{Discussion Of Results}

The result of the analysis is presented in Figure 2. The thermal conductivities of the sample for all the species of wood considered are plotted against the particle sizes. It was revealed that almost all the samples have their highest thermal conductivity at $300 \mu \mathrm{m}$ with Celtics zenkeri recording the highest thermal conductivity value of $0.14 \mathrm{Wm}^{-1} \mathrm{~K}^{-1}$ while Milicia excels and Pterygota macrocarpa had very close conductivity values of 0.062 and $0.063 \mathrm{Wm}^{-1} \mathrm{~K}^{-1}$. For particle size $850 \mu \mathrm{m}$, Celtics zenkeri still recorded the highest thermal conductivity value of $0.119 \mathrm{Wm}^{-1} \mathrm{~K}^{-1}$. These values fall within the range of the thermal conductivities of materials used as thermal insulators in solar cell development and applications. It is established in this study that the thermal conductivity of the sawdust samples is lower compared with their bulk wood material as reported by Oluyamo et. al., (2012). Amongst the particle sizes considered, all samples have their lowest thermal conductivity value ranging between $0.045-0.067 \mathrm{Wm}^{-1} \mathrm{~K}^{-1}$ at $600 \mu \mathrm{m}$ except for Pterygota macrocarpa. Thermal insulation of each sample at different particle sizes is presented in Figure 3. Significant variation in thermal conductivity of samples of the same species as the particle sizes change was noticed in the study. It was also observed that there exist no definitive pattern of variation with particle sizes, however, except for the Pterygota macrocarpa and Pterocarpus osun samples, all the wood species have low thermal conductivities at $600 \mu \mathrm{m}$.

Table 1 contains the result of the thermal conductivity of samples considered with respect to their particle sizes. Comparing the result in this study with the thermal insulation property of some commonly used materials for flat plate solar collector as presented in Table 2, all samples with particle size of $600 \mu \mathrm{m}$ and conductivity values which ranges between $0.045-0.067 \mathrm{Wm}^{-1} \mathrm{~K}^{-1}$ fall within the range of already established flat plate solar collectors; although, slight variation was noticed for the Pterygota macrocarpa sample. It is interesting to note in this study that Milicia excels could serve as the best material for use as flat plate solar collector for all the particle sizes considered. Hence, it can be deduced that all samples considered are good thermal insulators with 
thermal conductivities ranging between $0.045199-0.147759 \mathrm{Wm}^{-1} \mathrm{~K}^{-1}$. The values of the thermal resistivity of the samples considered in the study also reveals the potentials of the materials for use as heat resistant in device applications.

\section{Conclusion}

Particle sizes consideration can be of great importance in improving the insulation properties of wood materials. This will surely add to its economic value rather than constituting menace in the environment. Different wood species have varying thermal properties; hence analysis of these materials needs to be separated by species type. In this study, except for the Pterygota macrocarpa sample, the species of wood considered at specific particle sizes, exhibit low thermal conductivity that is comparable with materials used as insulator in industrial solar flat plate collectors. They could also be used in lagging of refrigerator, incubator, cooler, food flask e.t.c. Sawdust also exhibit high thermal resistivity value which could serve as potential sources of heat resistants in device applications.

Table 1: Thermal conductivity of the samples analysed at different particle sizes.

\begin{tabular}{|c|c|c|c|c|c|c|c|}
\hline \multicolumn{2}{|l|}{ Samples } & \multicolumn{2}{|c|}{$300 \mu \mathrm{m}$} & \multicolumn{2}{|c|}{$600 \mu \mathrm{m}$} & \multicolumn{2}{|c|}{$850 \mu \mathrm{m}$} \\
\hline Botanical Name & Yoruba & $\begin{array}{l}\text { Thermal } \\
\text { conductivity } \\
\left(\mathrm{Wm}^{-1} \mathrm{~K}^{-1}\right)\end{array}$ & $\begin{array}{l}\text { Thermal } \\
\text { Resistivity } \\
\left(\mathrm{mKW}^{-1}\right)\end{array}$ & $\begin{array}{l}\text { Thermal } \\
\text { conductivity } \\
\left(\mathrm{Wm}^{-1} \mathrm{~K}^{-1}\right)\end{array}$ & $\begin{array}{l}\text { Thermal } \\
\text { Resistivity } \\
\left(\mathrm{mKW}^{-1}\right)\end{array}$ & $\begin{array}{l}\text { Thermal } \\
\text { conductivity } \\
\left(\mathrm{Wm}^{-1} \mathrm{~K}^{-1}\right)\end{array}$ & $\begin{array}{l}\text { Thermal } \\
\text { Resistivity } \\
\left(\mathrm{mKW}^{-1}\right)\end{array}$ \\
\hline Milicia excels & Iroko & 0.062306 & 16.04994 & 0.050909 & 19.64298 & 0.068575 & 14.58264 \\
\hline Pterygota macrocarpa & Oporoporo & 0.06292 & 15.89319 & 0.095183 & 10.50607 & 0.097439 & 10.26285 \\
\hline Pterocarpus mildraedii & Ure & 0.075806 & 13.19159 & 0.054109 & 18.48137 & 0.092158 & 10.85094 \\
\hline Alstonia boonei & Ahun & 0.085874 & 11.64501 & 0.050767 & 19.69781 & 0.071665 & 13.95377 \\
\hline Pterocarpus osun & Osun & 0.107409 & 9.310183 & 0.06775 & 14.7602 & 0.061002 & 16.39291 \\
\hline Celtics zenkeri & Ita & 0.147759 & 6.767784 & 0.045199 & 22.12437 & 0.119679 & 8.355665 \\
\hline
\end{tabular}

Table 2: Thermal Conductivity of Common Insulator Materials used in Flat Plate Solar Collector

\begin{tabular}{ll}
\hline Material & Thermal conductivity $\left(\mathbf{W m}^{-1} \mathbf{K}^{-1}\right)$ \\
\hline Mineral wool (clay wool, fibre glass, rock wool & $0.0322-0.0404$ \\
Hair felt & 0.0389 \\
Granulated cork & 0.0476 \\
Re-granulated cork $(0.47 \mathrm{~cm}$ particles) & 0.04471 \\
Compressed cork & $0.0418-0.0462$ \\
Straw & 0.0576 \\
Sawdust & 0.0649 \\
Vermiculite (granulated) & 0.0721 \\
Polyurethane foam (rigid) & 0.0245 \\
Polystyrene (expanded) & 0.0303 \\
\hline
\end{tabular}

\section{Adapted from [16]}

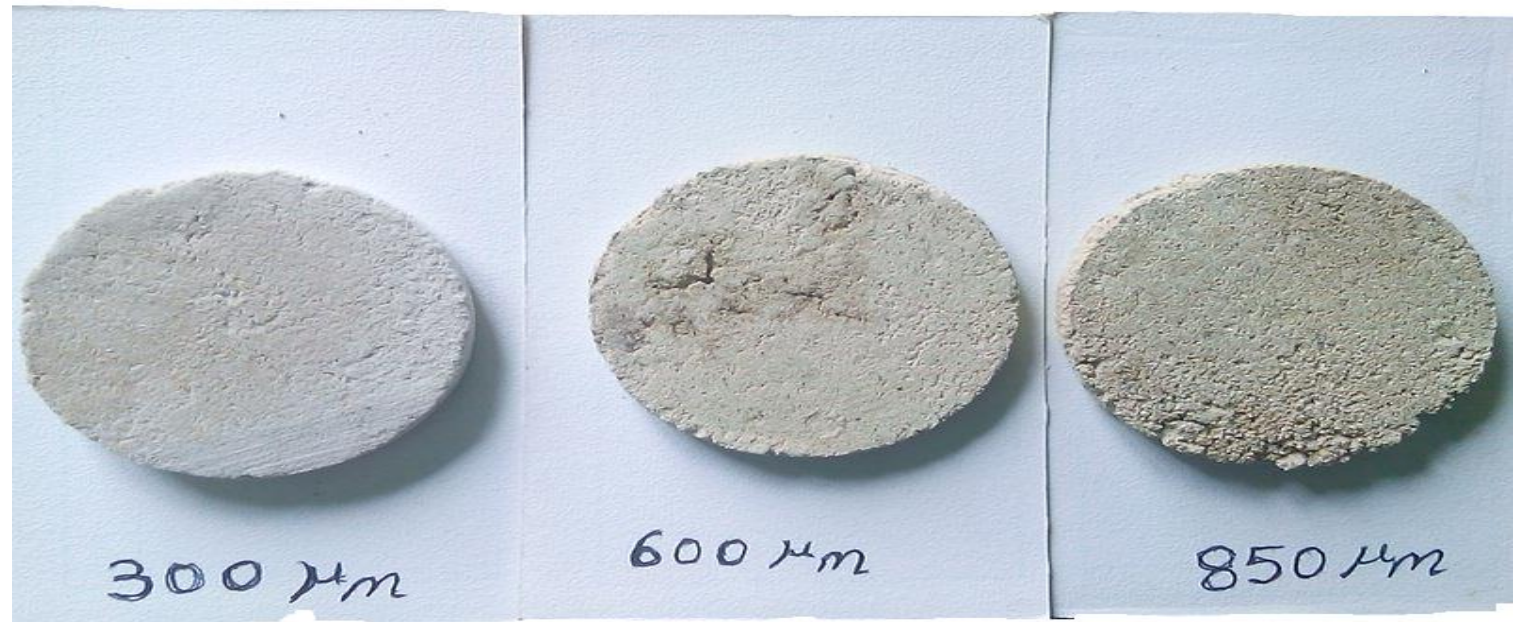

Figure 1: Final disc shape of the samples for different particle sizes 


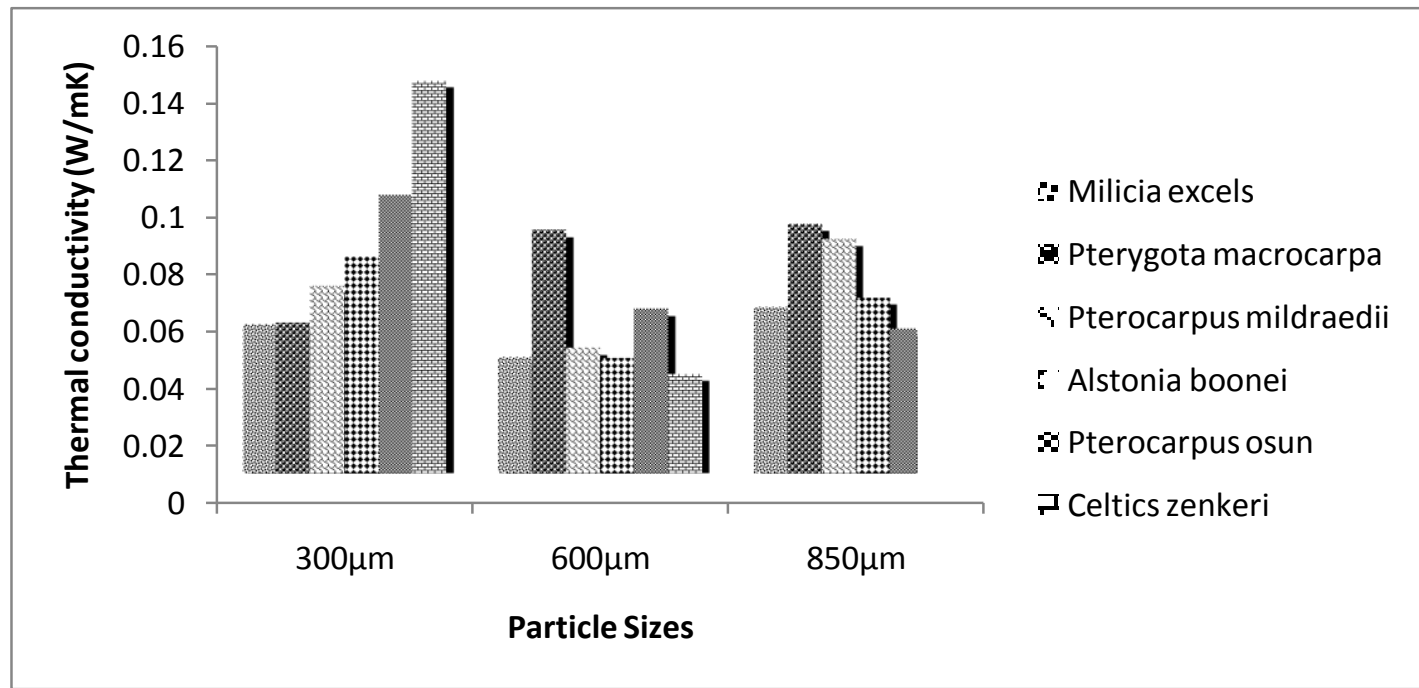

Figure 2: Thermal conductivities of samples at 300, 600 and $850 \mu \mathrm{m}$ particle sizes

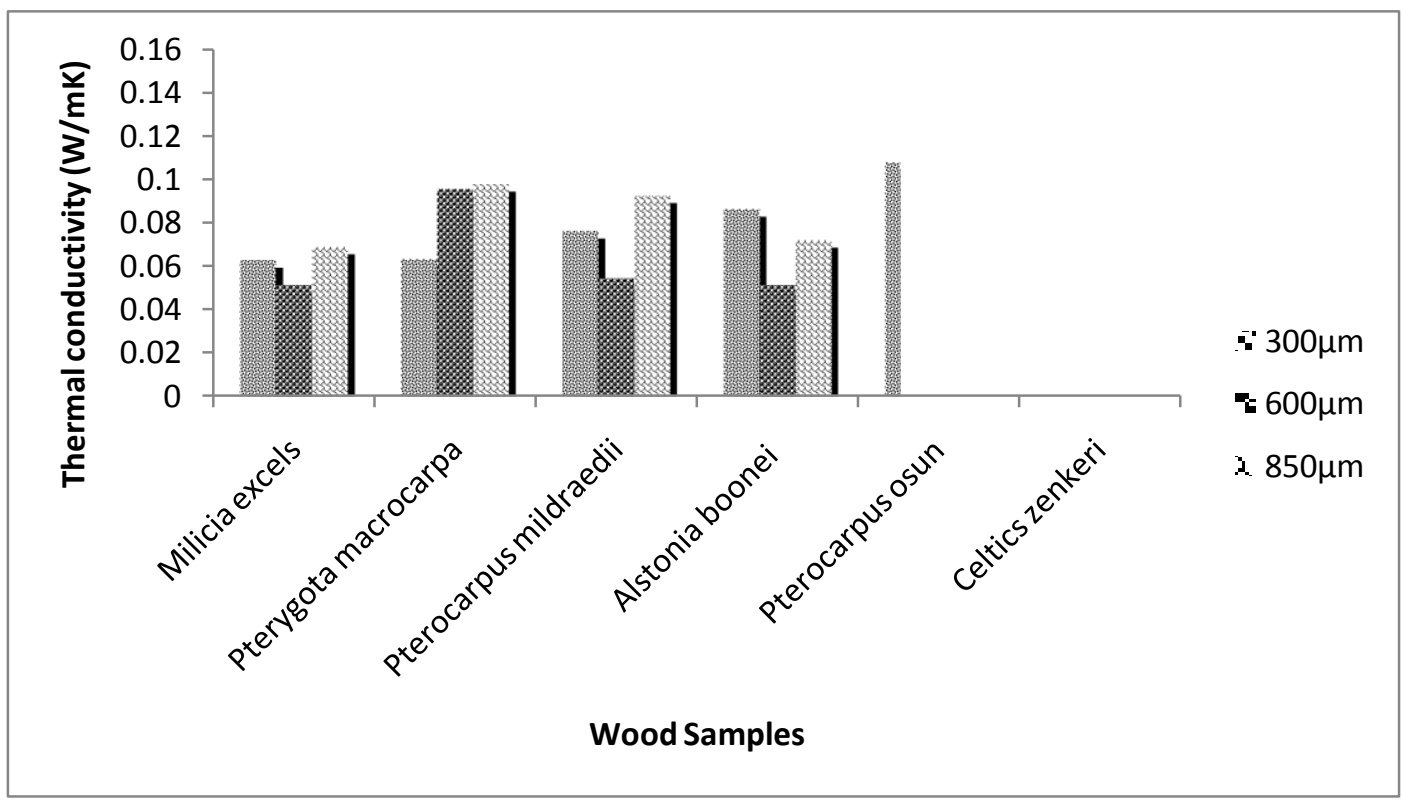

Figure 3: Thermal Conductivities of different particle sizes for each wood sample

\section{References}

[1] W. C. Turner and J. F. Malloy, Thermal Insulation Handbook (McGraw-Hill Book Company New York, 1988).

[2] A. J. Chapman, Heat Transfer, $4^{\text {th }}$ Edition (Macmillan Publishing Company, New York, 1984), 4

[3] Kamal Al-Malah and Basim Abu-Jdayil, Clay-based heat insulator composites: Thermal and water retention properties. Applied Clay Science, 37, 2007, 90-96.

[4] J. C. McDonalds, Lung dust analysis in the assessment of past exposure of man made mineral fibres workers. Annals occupation of hygiene, 34, 1990, 427- 441 .

[5] R. Sumrerng and C. Prinya, Strength and carbonation model of rice husk ash cement mortar with different fineness. Materials in civil engineering, 2010, 253-259.

[6] S. E. Etuk and L. E. Akpabio, Investigation of Ceiba pentandra cotton as a Potential Thermal Insulator. Journal of Raw Materials Research, 1(1), 2004, 4-10.

[7] K. Ajibola and B. O. Onabanjo, Investigation of Cocos nucifera as a potential insulator for buildings. Ren. Energy. 6(1), 1995, 8184.

[8] S. S. Oluyamo, O. R. Bello and O. J. Yomade, Thermal Conductivity of Three different Wood Products of Combretaceae Family; Terminalia superb, Terminalia ivorensis and Quisqualis indica Journal of Natural Sciences Research, 2(4) 2012, 36-43.

[9] I. O. Ogunleye and O. Awogbemi, Thermo-physical properties of eight varieties of sawdust. Journal of Research in Engineering, 4, 2007, 9-11.

[10] D. P. Daniel, "Perfect! Wood Win-Door Profiles" (Trace Laboratories, INC 5 North Park Drive Hunt Valley, MD 21030, USA, 2010), 1-5.

[11] L. L. Baxter, Influence of ash deposit chemistry and structure on physical and transport properties. Fuel Process. Technol, 56, 1998, $81-88$. 
[12] S. Torquato, Random heterogeneous media: Microstructure and improved bonds on the effective properties. Appl. Mech, 44, 1991, 37-76.

[13] Griffin and Goeorge, Lee's Conductivity Apparatus (ElectricalMethod), LL44-590I.S. 1122/7302, (Griffin and George Ltd, Wembley, Middlesex UK, 2002), 2-4.

[14] M. P. Duncan and M. Jarratt, Thermal conductivity of PTFE and PTFE composites. Thermochimica Acta 392-393, 2002, $231-236$.

[15] F. A. Tyler, Laboratory Manual of Physics, $4^{\text {th }}$ Ed. (Edward Arnold, London, 1971)

[16] A. A. M. Sayigh, The Technology of Flat Plate Collector in Solar Energy Conversion, An Introductory Course (University of Waterloo Ontario, Canada, 1978), 108 